\title{
The Farmer-Input Subsidy Program (FISP) Does not Service the Poor
}

\author{
Mercia Andrews ${ }^{1}$
}

Published online: 27 October 2021

(c) Society for International Development 2021

\begin{abstract}
This article focuses on the Farmer Input Subsidy Program (FISP) in Southern Africa. The FISPs are part of agricultural support by governments providing input subsidies to small-scale farmers from public resources. FISPs are intended to reduce the production costs of small-scale farmers. Rural women members of the Rural Women's Assembly (RWA) in Southern Africa argue that the FISP is captured by the global agro-industry and that the FISP, far from providing real support to farmers, advances a green-revolution agenda and has become a tool of the political elites and MNCs.
\end{abstract}

Keywords Agriculture subsidies $\cdot$ Agro-ecological production agriculture $\cdot$ Rural women $\cdot$ Poverty

This article is based on reports of public advocacy events that were hosted by the Southern African Rural Women's Assembly (RWA) during the SADC Heads of State Annual Summit in August 2021. The RWA is a rural movement of small-scale farmers, peasants, farm workers, fisher women and small traders that have members in ten countries in Southern Africa. The RWA is a grass-roots movement that challenges patriarchy and promotes food and seed sovereignty.

The RWA organized a series of side events as part of the parallel people's summit that is hosted annually by Southern Africa People's Solidarity Network (SAPSN). ${ }^{1}$ This parallel summit is a space that civil society organizations use to mobilize around their issues, raise concerns and challenges but also engage directly with governments and especially with the SADC Secretariat who hosts the Head of States Annual Summit. This year the SADC Heads of State Summit was in Malawi hence the parallel people's summit also took place in Malawi. The RWA hosted three interlinking events between the 17th and19th of August. The theme of the three processes was: Re-imaging the food system. This year the RWA organized some of the sessions in partnership with other movements such as Alliance for Food Sovereignty in Africa (AFSA) and East and Southern African Farmers Forum (ESAFF). However, the sessions were interrelated,

Mercia Andrews

mercia@tcoe.org.za

1 Trust for Community Outreach and Education, Cape Town, South Africa and the movement attempted to draw attention to the link between the UN Food Systems Summit (UNFSS) and the Farmer Input Subsidy Programs (FISPs) which the movements view as an example of the how agro-industry has captured the subsidy that is intended to small-scale farmers, peasants and rural women producers in Southern Africa. The RWA also used the space to highlight the growing challenges that poor, rural and urban households experienced as a result of the COVID-19 pandemic and the economic recession in Southern Africa.

Moreover, the reality that confronts poor people daily was confirmed by the latest State of Food Security and Nutrition in the World 2021 Report that puts forward statistics to indicate the world was off-track to eradicate hunger, food insecurity and malnutrition in all its forms by 2030 (FAO et al. 2021). The COVID pandemic has not simply made visible the existing deep inequalities between the haves and the have-nots, but also highlighted the extent of corporate control of the food system.

August 2021 was the fifth year that the RWA has mobilized hundreds of its members to protest at the SADC Heads of State Annual Summit against the way the FISP is used in Southern Africa. At the 2017 SADC Summit in South Africa, women invited a representative from SADC Secretariat to their gathering to hand over a petition of their demands. Since then, the RWA has protested, mobilized and attempted to expose the way much needed public resources and inputs failed to reach poor, women small-scale farmers.

\footnotetext{
$\overline{1}$ RWA programme at SAPSN, in Malawi, August 2021.
} 


\section{Farmer Input Subsidy Program in Southern Africa}

The FISP is a policy framework that was first discussed at a ministerial level by African Ministers assembled under a special session of the FAO Regional Conference for Africa in Rome in 2002. The motivation was for governments to allocate $10 \%$ of their budgets to support agricultural development in Africa. Several of the processes which were led by Ministers of Agriculture, and included FAO and other stakeholders, culminated in the adoption of the Maputo Declaration in 2003. In the period after the adoption of the Maputo Declaration the hope was to increase and have greater expenditure on agriculture but also according to the World Bank Group (2021) introduce 'smarter' input programmes. These proposals from governments highlighted the need to put in place strategies, plans and policy frameworks to fight hunger and poverty in Africa (ACB 2016).

The implementation of the FISP in the region has evolved over the past decade but what is clear, however, is the fact that 'implementation of agricultural input subsidies across Africa is probably best described as patchy' (Dorward and Chirwa 2014). The way the FISP is delivered and implemented is also not uniform in the region. In some countries the agriculture departments offer a flat-rate or universal price subsidy while others ration supplies to targeted farmers and also distribute the same seeds/crops. In some countries they make use of vouchers. Some rely on and seek to develop the private sector for fertilizer and seed supply, while others rely on parastatals (Dorward and Chirwa 2014; ACB 2016).

A number of countries in the SADC region implement the FISP and a wide range of approaches and strategies for implementation of the subsidies are used. The Zambian $\mathrm{e}$-voucher is evidence of this.

In Zambia, according the RWA farmers, the FISP is administered through vouchers or coupons that enable eligible households to purchase fertilizer, hybrid seed, and pesticides at reduced prices. The programme focuses on smallholder farmers who own land and live in their villages. This e-voucher system was first piloted during 2015/2016 and has continued until recently. The e-voucher system uses a mobile delivery and tracking system to distribute subsidized products through private-sector suppliers to targeted farmers and is meant to be more efficient and effective. It is an electronic system that can be accessed on mobile phones and is said to allow for real time registration of beneficiaries and electronic payment to the agro-dealers and retail agents who distribute the products.

According to the Malawi Strategy Support Program of the International Food Policy Research Institute in 2008, a total of 150,000 tons of maize fertilizer and 20,000 tons of tobacco fertilizer were acquired by the Malawi Government for distribution to smallholder farmers through the FISP. This again highlights the other inconsistences besides the implementation as the FISP was intended to focus on food crops.

Despite these difference in approach and strategies in how the FISP is implemented in the region, poor women farmers are dependent on these input subsidies to allow them to continue their production and support their households. A recent World Bank Discussion Note (2021), citing Zambia, argues that substantial public resources are used to drive FISP. This World Bank Discussion Note states that in 2019, the Zambian Ministry of Agriculture used more funds on FISP than on agriculture itself.

It is therefore legitimate to challenge whether FISPs are meeting their objectives of promoting pro-poor economic growth, decreasing food prices, enhancing food security and input adoption, increasing the efficiency of input use, developing the input supply system, boosting producer welfare, improving soil fertility, and providing political benefits (ACB 2016; FAO 2014; Chirwa and Dorward 2013). We also have to ask whether FISPs that are designed to raise household, national food security and food self-sufficiency by improving resource-poor smallholder farmer's access to improved agricultural inputs (AGRA 2017) are reaching poor women small -scale farmers and peasants?

\section{Rural Women's Assembly Says FISP is Failing Them}

Since its founding assembly in 2009 in Limpopo, South Africa, the RWA has monitored the delivery of farmer input subsidies. As a result, the RWA members are of the view that the FISP is an example of how the food system is captured by the local and global elites and agro-industry.

As mentioned, each year during the SADC Heads of States Summit RWA members use the parallel people's summit as a space to raise concerns and problems that they experience in their respective countries. The 2021 mobilizations, organized in August, wanted to focus on reviewing on what had changed for the farmers, especially women farmers given that RWA had attempted to engage the SADC Secretariat over the past five years. The RWA involved partners such as AFSA, ESAFF, the African Centre for Biodiversity (ACB) and other movements and groups in their processes.

\section{FISP Through the Experience of Zambian Farmers}

The RWA decided to focus on Zambia and asked the RWA Zambia to present a case study and invite farmers to speak about their concrete experiences. One of the leading 
members of RWA Zambia, Ms. Susan Chilala, a farmer, made the following remarks as part of her testimony: 'The Farmer Input Subsidy Program - FISP - in Southern Africa was not granted on a platter as a subsidy: peasant organisations, farmers 'movements fought for funds to support and develop agriculture. This is why farmers have to remind their governments of the Maputo and Malebo Declarations. We have struggled over the years to ensure that funds from agriculture budgets were allocated to small-scale farmers. We have also fought for the recognition of women farmers as equal producers of food, to not be overlooked when the FISP is implemented.'

Mary Sakala, another farmer and member of RWA, spoke about her experiences. Mary and her family farm on a 20-hectare farm in the Shimbizhi-Mumbwa region. She explains that even though FISP is intended for the most vulnerable farmers, smallholders and poor farmers mostly dependent on subsistence farming, the subsidy does not reach these farmers. She claims that the subsidy programme in Zambia can be described as filled with corruption and that it is often used as a political tool by the local authorities. According to her, there is clear evidence that those part-time farmers with jobs and even commercial farmers are the main beneficiaries of the subsidy. She also makes the argument that in the last period the market has become very skewed, and farmers have to pay very high prices for fertilizers. These sharp increases in the cost of fertilizers have made it very difficult for people to actually receive anything meaningful from this from the subsidy. She went on to explain the FISP in Zambia. Each farmer must pay 25 US Dollars to be eligible for the FISP package, which consists of $10 \mathrm{kgs}$ maize seeds; $50 \mathrm{~kg}$ soyabeans; 4 bags of basal fertilizers and 4 bags of top dressing. One can choose between soyabeans and groundnuts. She complained that the package they receive consists mainly of fertilizers, hybrid seeds (mainly maize), and that this past season the groundnut seeds did not even germinate. Moreover, Mary stated that she can see a deterioration of topsoil quality and other general ecological problems. She also made the point that farmers or beneficiary selection is carried out by village heads and members of village development committees and the selection is meant to give priority to 'vulnerable' groups.

The Zambian RWA members all concurred with Mary Sakala when she said that often women are overlooked and those distributing the FISP would expect 'favours' from women farmers. Others made the point that there was no consultation, and the attitude of the Ministry of Agriculture was 'take it or leave it'. This was especially the case when it was argued that it was important to provide choice given that some of the farmers promote agroecological farming and that the RWA was organizing itself locally to integrate its farmer-managed seed systems that focused on local, traditional seeds and non-GMO seeds. She also reported that many of the seeds distributed were hybrid seeds.

She spoke about the fact that in recent years the e-voucher system that was experimented with was unfortunately stopped, even though the e-vouchers allowed for greater flexibility because the system did not have a 'prescribed package' as described above. It provided the farmers with options. Another sore point that the farmers raised was about agriculture insurance. She spoke about the fact that the current insurance scheme consists of 1 million members and each farmer contributes \$5 USD. Yet when they recently experienced a recent disaster, the insurance scheme only paid them with a bag of onions.

The farmers from RWA Swaziland (eSwatini) also raised their concerns. They supported the views of Mary Sakala by highlighting the fact that in Swaziland the price of fertilizers and other inputs had increased dramatically. The Swaziland farmers also focused on the fact that many of the inputs were not sourced locally in Swaziland or even in the region. Instead, the inputs delivered to farmers came from Indian companies. For them, this factor illustrated the fact that local companies were not benefitting from the resources allocated to FISP. This was a big concern because Swaziland farmers were of the view that a large percentage of the agriculture budget goes to the FISP.

\section{Concerns Raised by the RWA Members}

In the general discussion, the women raised several concerns that the RWA campaign had to consider. The first was the fact that the FISP in the region concentrated on maize and soyabeans mainly. It would appear very much in line with the 'green revolution' approach of distributing maize seeds and fertilizers to expand the maize production at the expense of other crops. Fertilizers were promoted despite the growing climate crisis in the region, with more severe droughts that are followed by floods. The FISP was controlled by the large-scale commercial farmers that wanted to benefit from the subsidies and were producing for the export market.

The FISP was used as to promote political patronage and 'subservience' - some farmers claim that members of the ruling parties receive subsidies over and above those that are not members. Some of the members extended this point and argued that it created dependence and created indebtedness but also the FISP created unequal partnerships with countries that were providing financial support to poor countries.

The RWA was of the view that FISP also undermining alternatives such as agroecology, farmer-managed seeds and dietary diversity and climate resilience. 


\section{Going Forward}

What is clear to the RWA is that the mobilization to challenge the FISP has to be based on building strong alliances with peasant and farmer movements in the region. Agriculture in SADC is a priority sector for job creation and for export volumes and earnings. It plays a crucial role in economic growth and poverty reduction (Malabo Declaration 2014). However, the expectation that, through programmes such as FISPs, smallholders will be able to feed their families, accumulate a surplus to sell, and gain an income to move out of poverty is going to be a fallacy if the decisionmakers throughout the SADC countries do not adopt more differentiated policies and if the farmer movements, especially the radical voices, do not represent a direct challenge to the governments in the region.

\section{References}

ACB. 2016. Farm Input Subsidy Programmes (FISPs): A Benefit for, or the Betrayal of, SADC's Small-Scale Farmers? Johannesburg: ACB. https://www.acbio.org.za/wp-content/uploads/2016/07/ Input-Subsidies-Report-ACBio.pdf. Accessed 26 October 2020.

AGRA. 2017. Improvement of Malawi's Farm Input Subsidy Program (FISP) - Learning from ISP best practices, Nairobi: AGRA,
file://C:/Users/STEFAN 1/AppData/Local/Temp/Improvementof-Malawis-Farm-Input-Subsidy-Program-FISP.pdf

Chirwa, Ephraim W., and Andrew R. Dorward. 2013. Agricultural Input Subsidies. The Recent Malawi Experience. New York: Oxford University Press.

Dorward, Andrew R., and Ephraim W. Chirwa. 2014. The Impacts of the Farm Input Subsidy Programme, 2005/6 - 2012/13. FISP Policy Brief 2014/1. https://www.soas.ac.uk/cedep/research/ malawi-subsidies/file90371.pdf.

FAO. 2014. Strengthening coherence between agriculture and social protection - Zambia Case Study Report, Rome: FAO file://C:/ Users/STEFAN 1/AppData/Local/Temp/i5164e-1.pdf

FAO, UNDP and UNEP. 2021. A multi-billion-dollar opportunity - Repurposing agricultural support to transform food systems. Rome, FAO. https://doi.org/10.4060/cb6562en

Malabo Declaration on Accelerated Agricultural Growth and Transformation for Shared Prosperity and Improved Livelihoods. 2014. Midrand: NEPAD. https://www.nepad.org/caadp/publication/ malabo-declaration-accelerated-agricultural-growth

World Bank. 2021. Global Economic Prospects, June 2021. Washington, DC: World Bank. doi:https://doi.org/10.1596/978-1-46481665-9. License: Creative Commons Attribution CC BY 3.0 IGO.

Publisher's Note Springer Nature remains neutral with regard to jurisdictional claims in published maps and institutional affiliations. 